\title{
Chemical and Electrochemical Properties of La0.58Sr0.4Fe0.8Co0.2O3- (LSCF) Thin Films upon Oxygen Reduction and Evolution Reactions
}

Pitscheider, Simon; Machala, Michael; Guan, Zixuan; Chen, Di; Hjelm, Johan; Jacobsen, Torben; Chueh, William C.; Mogensen, Mogens Bjerg; Chatzichristodoulou, Christodoulos

Publication date:

2017

Document Version

Publisher's PDF, also known as Version of record

Link back to DTU Orbit

Citation (APA):

Pitscheider, S., Machala, M., Guan, Z., Chen, D., Hjelm, J., Jacobsen, T., Chueh, W. C., Mogensen, M. B., \& Chatzichristodoulou, C. (2017). Chemical and Electrochemical Properties of $\mathrm{La}$, $S r$, Fe Co $\mathrm{O}$ (LSCF)

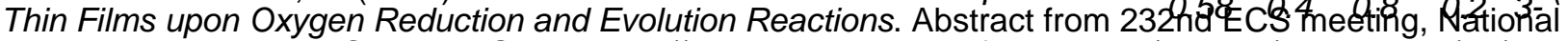
Harbor, Washington, DC, United States. http://ma.ecsdl.org.proxy.findit.dtu.dk/content/MA2017-02/39/1742

\section{General rights}

Copyright and moral rights for the publications made accessible in the public portal are retained by the authors and/or other copyright owners and it is a condition of accessing publications that users recognise and abide by the legal requirements associated with these rights.

- Users may download and print one copy of any publication from the public portal for the purpose of private study or research.

- You may not further distribute the material or use it for any profit-making activity or commercial gain

- You may freely distribute the URL identifying the publication in the public portal 
Click here to print this page now.

You have submitted the following abstract to 232nd ECS Meeting (October 1-6, 2017), . Receipt of this notice does not guarantee that your submission was complete, free of errors, or accepted for presentation.

\section{Chemical and Electrochemical Properties of $\mathrm{La}_{0.58} \mathrm{Sr}_{0.4} \mathrm{Fe}_{0.8} \mathrm{Co}_{0.2} \mathrm{O}_{3-\delta}$ (LSCF) Thin Films upon Oxygen Reduction and Evolution Reactions}

S. Pitscheider (DTU Energy - Technical University of Denmark), M. Machala (Materials Science and Engineering - Stanford University), Z. Guan (Stanford University), D. Chen (Materials Science and Engineering - Stanford University), J. Hjelm (DTU Energy, Technical University of Denmark), T. Jacobsen (DTU Chemistry, Technical University of Denmark), W. C. Chueh (Stanford University), M. B. Mogensen (Technical University of Denmark), and C. Chatzichristodoulou (DTU Energy, Technical University of Denmark)

\section{Abstract Text:}

The Oxygen Evolution and Oxygen Reduction Reactions (OER/ORR), occurring at the oxygen electrode of Solid Oxide Cells (SOCs) in the two possible ways of operation, require substantial overpotentials, therefore lowering the operating efficiency of the cells. The reaction mechanisms occurring at these electrodesare still not completely understood due to their complexity and localized character at the interfaces between different materials or between the gas atmosphere and the electrocatalyst, and need in situ techniques with very high chemical sensitivity, with the additional difficulty of probing the materials as close as possible to their realistic operating conditions.

In addition, the properties of LSCF are, despite numerous studies, still unclear in many aspects, despite LSCF being one of the state-of-the-art electrocatalysts used for SOCs. It is understood that the surface chemical composition deviates from the nominal bulk composition, and that secondary phases can segregate at the surfaces and interfaces during operation. Furthermore, the electrochemical properties such as Area Specific Resistance (ASR), oxygen exchange coefficient $\left(k_{e x}\right)$, ASR activation energy $\left(E_{a}\right)$ and $\mathrm{pO}_{2}$ exponents for LSCF reported in the literature vary considerably.

This study aims to better understand the properties of LSCF, by combining the results of Electrochemical Impedance Spectroscopy (EIS) and Near-Ambient Pressure X-ray Photoelectron Spectroscopy (NAP-XPS) on model electrodes, both in polarized and unpolarized conditions. In particular, NAP-XPS studies of the surface chemistry evolution under operation, as well as the correlation between surface potential changes in relation to the applied overpotential are addressed, in an attempt to determine the real driving force for the oxygen reactions.

For this purpose, thin films of LSCF are deposited by Pulsed Laser Deposition (PLD) through shadow masks, in order to obtain well-defined electrode geometries with low risk of contamination, and subsequently tested both in highly clean EIS measuring setups and at the synchrotron beamline. The results of both kinds of experiments are correlated, the goal being a better understanding of the material's properties under operation, as well as possible degradation phenomena.

\section{Acknowledgements:}

We gratefully acknowledge financial support from ECoProbe (DFF - 4005-00129) funded by the Danish Independent Research Council, Otto Mønsteds Fond (17-70-0196) and SUNCAT in collaboration with the Danish Agency for Science and Higher Education (7032-00001B)

\section{Symposium Selection:}

I02: Ionic and Mixed Conducting Ceramics 11 (IMCC 11)

Submitter's E-mail Address:

sipi@dtu.dk

\section{Preferred Presentation Format:}

Oral 
Mr. Simon Pitscheider

Affiliation(s): DTU Energy - Technical University of Denmark

Address:

Lysalleen 322

Roskilde, 4000

Denmark

Phone Number: 93511417

E-mail Address: sipi@dtu.dk

Second Author

Michael Machala

Affiliation(s): Materials Science and Engineering - Stanford University

Phone Number:

E-mail Address: mmachala@stanford.edu

Third Author

Mr. Zixuan Guan

Affiliation(s): Stanford University

Phone Number: 650-7399697

E-mail Address: zxg@stanford.edu

Fourth Author

Di Chen

Affiliation(s): Materials Science and Engineering - Stanford University

Phone Number:

E-mail Address: dichen16@stanford.edu

Fifth Author

Dr. Johan Hjelm

Affiliation(s): DTU Energy, Technical University of Denmark

Phone Number: 004546775887

E-mail Address: johh@dtu.dk

Sixth Author

Dr. Torben Jacobsen

Affiliation(s): DTU Chemistry, Technical University of Denmark

Phone Number:

E-mail Address: tj@kemi.dtu.dk

Seventh Author

Dr William C Chueh

Affiliation(s): Stanford University

Phone Number: 650-725-7515

E-mail Address: wchueh@stanford.edu

Eighth Author

Prof. Mogens Bjerg Mogensen

Affiliation(s): Technical University of Denmark

Phone Number: +45 21326622

E-mail Address: momo@dtu.dk

Ninth Author

Dr. Christodoulos Chatzichristodoulou

Affiliation(s): DTU Energy, Technical University of Denmark

Phone Number: 46775893

E-mail Address: ccha@dtu.dk 
- To access your submission in the future, use the direct link to your abstract submission from one of the automatic confirmation emails that were sent to you during the submission.

- Or point your browser to /ecs/reminder.cgi to have that URL mailed to you again. Your username/password are 105962/144096.

Any changes that you make will be reflected instantly in what is seen by the reviewers. You DO NOT need to go through all of the submission steps in order to change one thing. If you want to change the title, for example, just click "Title" in the abstract control panel and submit the new title.

When you have completed your submission, you may close this browser window.

Tell us what you think of the abstract submittal

Home Page 